\title{
ARTICLE OPEN \\ Discovery of a lunar air temperature tide over the ocean: a diagnostic of air-sea coupling
}

\author{
T. Sakazaki (iD) ${ }^{1,2,3,4}$ and K. Hamilton ${ }^{1}$
}

The lunar semidiurnal $\left(L_{2}\right)$ tide in the Earth's atmosphere is unique as a purely mechanically forced periodic signal and it has been detected in upper atmosphere winds and temperature and in surface barometric pressure. $L_{2}$ signals in surface air temperature, $L_{2}(T)$, have only been detected at a single land station (results published almost a century ago). We report observational determinations of $L_{2}(T)$ over the ocean by using data from 38 moored buoys across the tropical Pacific and Atlantic. In contrast to published speculation that $L_{2}(T)$ should be negligible over ocean, we find that the observed $L_{2}(T)$ is fairly close to that consistent with an adiabatic $L_{2}$ pressure variation. Any deviations from purely adiabatic behavior are a measure of diabatic effects on the surface air-expected to be dominated by damping processes, notably heat exchange with the ocean surface. With the aid of climate model simulations that include $L_{2}$-tide-like variations, we demonstrate that our observations of $L_{2}(T)$ provide a unique diagnosis for the strength of air-sea coupling and a useful constraint on climate model formulations of this coupling.

npj Climate and Atmospheric Science (2018)1:25; doi:10.1038/s41612-018-0033-9

\section{INTRODUCTION}

The gravitational pull of the moon excites tidal variations in atmospheric circulation with $L_{2}$ frequency (period $\sim 12.42 \mathrm{~h}$ ). These variations are small-typically an order of magnitude less than solar diurnal and semidiurnal variations (which are forced primarily by the daily cycle of solar heating). ${ }^{1,2}$ However the lunar tide is singular as a purely mechanically (i.e., adiabatically) forced monochromatic (i.e., single frequency) variation and so observations of the $L_{2}$ tide can provide uniquely valuable diagnostics of atmospheric behavior that enhance understanding of the atmospheric circulation. A historically important example is provided by long-standing observations of $L_{2}$ variations in surface geomagnetic field that have informed our understanding of the ionospheric dynamo and upper atmospheric winds. ${ }^{3}$ Very recently it has been demonstrated that the $L_{2}$ circulation variations in the troposphere modulate tropical rainfall, ${ }^{4}$ and the measurements of the $L_{2}$ rainfall variation provide a valuable constraint on the representation of moist convective processes in climate models. ${ }^{5}$

In this study, we focus on measurements of the $L_{2}$ tide in surface air and show that the results provide important information on the thermal coupling of the atmosphere with the underlying surface. The $L_{2}$ variation in surface air pressure, $L_{2}(p)$, has been reliably determined at many stations where very long records of hourly measurements are available and its geographical and seasonal dependence have been established $^{1,6-8}$ (Supplementary discussion for a brief review). The basic features of the observed $L_{2}(p)$ have been reproduced by simplified linear theory calculations of the response of the global atmosphere to the lunar gravitational forcing. 2,9,10 The $L_{2}$ surface air temperature cycle, $L_{2}(T)$, is expected to have an amplitude $\sim 0.01 \mathrm{~K}$ making it quite hard to detect among all the other atmospheric disturbances present. The only direct observational report so far was obtained at a single location, Batavia $\left(6^{\circ} \mathrm{S}, 106.5^{\circ}\right.$ E), by Chapman ${ }^{11}$ using hourly data during 1866-1928 and this determination had large uncertainty due to sampling noise (Note that a recent study ${ }^{4}$ estimated the size of the troposphere-average $L_{2}(T)$ based on global reanalysis model data). In this study, we analyzed long data records at many ocean buoys to determine accurate values of $L_{2}(T)$ over the tropical ocean.

The $L_{2}$ forcing will excite a linear wave response in the atmosphere whose air temperature perturbations near the surface ( $\hat{T}$ : complex amplitude) are governed by

$$
\hat{T}=\frac{i \omega}{i \omega+\beta} \hat{T}_{\mathrm{ad}},
$$

where $\omega$ is he frequency $\left(=2 \pi / 12.42 \mathrm{~h}^{-1}\right)$, and $\hat{T}_{\text {ad }}$ is the adiabatic component defined as,

$$
\hat{T}_{a d} \equiv \frac{R \bar{T}}{C_{p} \bar{p}} \hat{p}
$$

where $\hat{p}$ is the complex amplitude of $L_{2}(p)$ (see Methods section for details). Because there is no "external" thermal forcing for $L_{2}$, the diabatic heating is expressed here as an effective Newtonian cooling with rate, $\beta$. Chapman ${ }^{12}$ suggested that (over land at least) $L_{2}(T)$ should to first order be in adiabatic relationship with $L_{2}(p)$, with deviations from this purely adiabatic behavior serving as a diagnostic of damping of the temperature signal in the air near ground (which he suggested would be dominated by heat exchange with the underlying surface). Chapman's single-station determination ${ }^{11}$ indeed showed a first order adiabatic relation between $L_{2}(T)$ and $L_{2}(p)$ but was not sufficiently precise to reliably determine the strength of any thermodynamic damping. Curiously Chapman $^{12}$ also suggested that air-sea coupling would be so strong that "over the oceans the lunar atmospheric tide will

\footnotetext{
'International Pacific Research Center, University of Hawai'i, Hawai'i 96822, USA; ${ }^{2}$ Japan Society for Promotion of Science Overseas Research Fellow, Chiyoda-ku, Tokyo, Japan and ${ }^{3}$ Research Institute for Sustainable Humanosphere, Kyoto University, Uji 611-0011, Japan Correspondence: T Sakazaki (zaki@kugi.kyoto-u.ac.jp)

${ }^{4}$ Present address: Graduate School of Science, Kyoto University, Kyoto 606-8502, Japan
}

Received: 2 January 2018 Revised: 28 February 2018 Accepted: 6 March 2018

Published online: 24 October 2018 

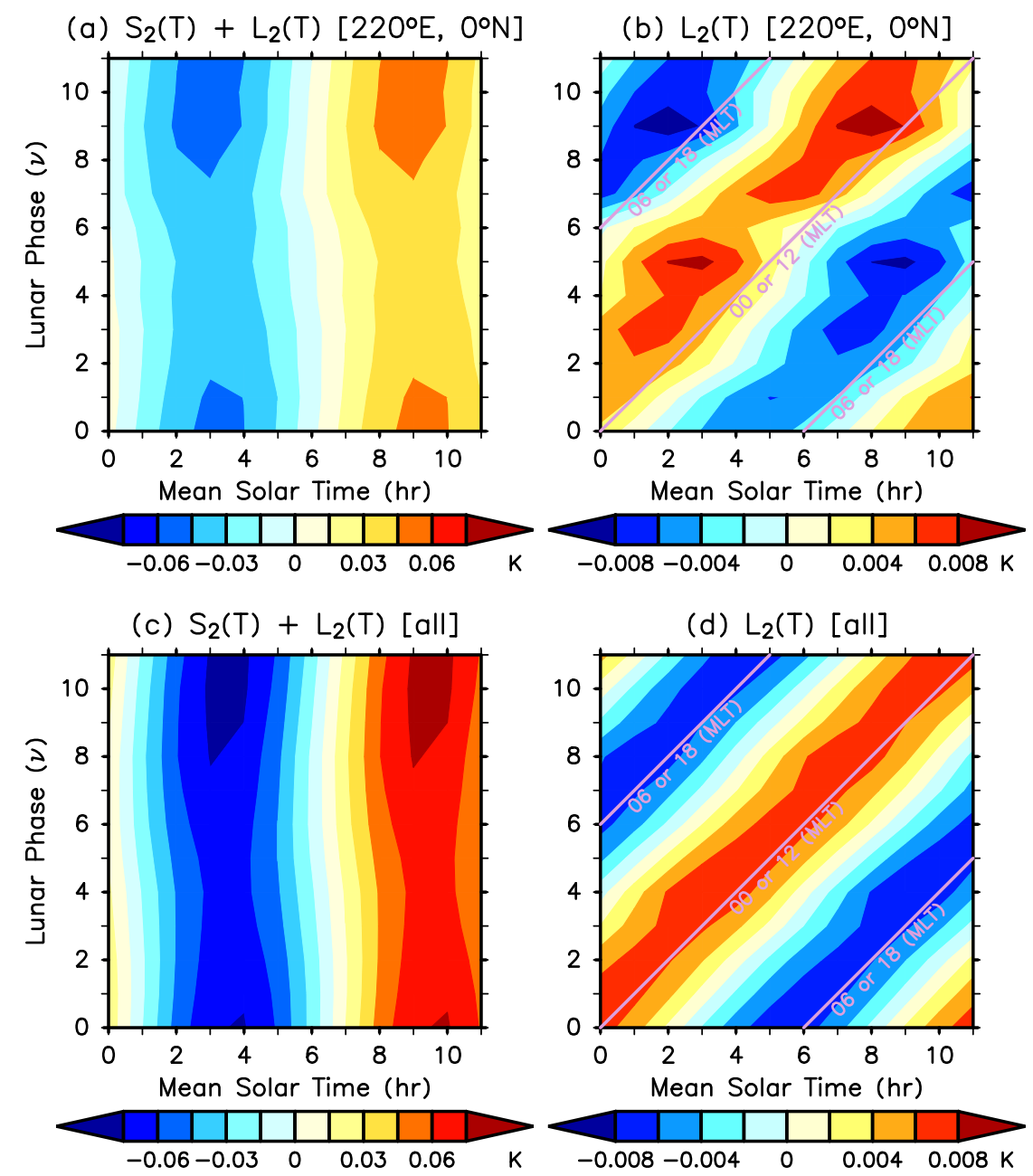

Fig. 1 a Semidiurnal harmonic of temperature observed at $\left(0^{\circ} \mathrm{N}, 220^{\circ} \mathrm{E}\right)$ as functions of mean local solar time (MLST) and lunar phase $(0$ is new/full moon and 6 is half-moon). b As is (a) but for the anomaly from the mean $S_{2}$ variation (computed as the average over the lunar phase). The mean local lunar time (MLLT) is shown by magenta lines. $\mathbf{c}, \mathbf{d}$ are as (a-b) but for the results averaged over the 38 buoy stations

appear to be isothermal at sea level". Our results will contradict this last assertion but will show that Chapman's idea of using determinations of $L_{2}(T)$ and $L_{2}(p)$ to infer damping rates can be useful if enough data are analyzed.

Note that for a propagating wave phenomenon such as the lunar tide, the thermodynamic "damping" effects, through either radiative transfer or sensible heat fluxes, will depend not just on the local $T^{\prime}$ but also on the $T^{\prime}$ in other layers of the atmosphere, and so the $\beta$ in (1) may be complex ${ }^{13,14}$ (the real part of $\beta$ must be positive, of course). In addition there is the possibility of an $L_{2}$ signal in latent heat release, although that is expected to be small in the (generally cloud/fog free ${ }^{15}$ ) air just above the tropical ocean.

\section{RESULTS: ANALYSIS OF BUOY DATA}

We have for the first time detected $L_{2}(T)$ over ocean by using data from dozens of moored buoy stations across the tropical Pacific and Atlantic. The observed 12-h harmonic determined from data during any day $\left(S_{2-o b s}\right)$ results from the superposition of true solar semidiurnal tide $\left(S_{2}\right)$ and the $L_{2}$ that is dependent on the lunar phase $(v)^{2}$, that is,

$$
\begin{aligned}
S_{2-\text { obs }}(\nu) & =S_{2}+L_{2}(\nu) \\
& =s_{2} \cos \left(\omega\left(t_{L T}-\phi_{2}\right)\right)+I_{2} \cos \left(\omega\left(\tau-\lambda_{2}\right)\right) \\
& =s_{2} \cos \left(\omega\left(t_{L T}-\phi_{2}\right)\right)+I_{2} \cos \left(\omega\left(t_{L T}-\lambda_{2}\right)-\nu \pi / 6\right)
\end{aligned}
$$

where $t_{L T}$ is mean local solar time (MLST in h), $s_{2}$ and $\varphi_{2}$ are amplitude and phase of $S_{2}, \tau$ is mean local lunar time (MLLT in $h$ ), $I_{2}$ and $\lambda_{2}$ are amplitude and phase of $L_{2}$, and $\omega=2 \pi / 12\left(\mathrm{~h}^{-1}\right)$. Here $v$ is an integer, increasing from 0 to 11 twice in each lunation (new moon to full moon and full moon to new moon) The relation, $t_{L T}=$ $\tau+v+12 n$ ( $n$ : integer), is used for the transformation. ${ }^{2}$ Figure 1 shows the $S_{2 \text {-obs }}$ and the anomaly from the average over the lunar phase at the buoy at $\left(0^{\circ} \mathrm{N}, 220^{\circ} \mathrm{E}\right)$ (panels a, b), as well as the results averaged over the 38 stations (panels $c, d$ ). Obviously the true $S_{2}$, the component independent of $v$, is dominant ( 0.05 K; Fig. 1a, c); however, the anomaly from $S_{2}(\sim 0.01 \mathrm{~K})$ clearly shows the lunar phase progression (Fig. 1b, d), indicating a significant $L_{2}$ signal even for single-station data. The temperature maximum of $L_{2}$ is observed around at 10:00 MLLT regardless of $v$ (see Methods section for details about the procedure for determining the amplitude and phase of $L_{2}$ ). The effects of beating between the true $S_{2}$ and $L_{2}$ signals appears as a modulation of the amplitude for the observed $S_{2}$ from maximum (spring tide) around $v=10$ to minimum (neap tide) around $v=4$ (Fig. 1a, c).

Figure 2a shows the observed $L_{2}(T)$ (red arrows) and $L_{2}(\mathrm{p})$ (blue arrows) over the tropical Pacific and Atlantic, as well as the uniform-grid $L_{2}(\mathrm{p})$ product developed by Schindelegger and Dobslaw $^{8}$ (SD16). The results are presented as harmonic dial vectors showing the amplitude and MLLT phase. $L_{2}(p)$ are converted to corresponding adiabatic temperature tide (referred to as $\left.L_{2}\left(T_{a d}\right)\right)$ using Eq. (2). $L_{2}(T)$ has a coherent structure with the 
phase at most stations being 10:00-12:00 MLLT. At the same time, a systematic geographical dependence is also obvious, particularly in the zonal direction; for example, both $L_{2}(T)$ and $L_{2}\left(T_{a d}\right)$ are stronger at $\sim 180^{\circ} \mathrm{E}$ and $\sim 220^{\circ} \mathrm{E}$ compared to $\sim 200^{\circ} \mathrm{E}$. Figure $2 \mathrm{~b}$ shows the scatter plot of $L_{2}(T)$ and $L_{2}\left(T_{a d}\right)$ at selected longitudes. It is seen that generally the amplitude of $L_{2}(T)$ is slightly smaller than that of $L_{2}\left(T_{a d}\right)$, with the phase of $L_{2}(T)$ earlier than that of $L_{2}\left(T_{a d}\right)$. This is consistent with a basic picture of an adiabatically forced mechanical wave slightly modified by thermal damping processes.

Figure 3 shows the $L_{2}(T)$ (from buoys) and $L_{2}\left(T_{a d}\right)$ (from both buoys and the SD16 grid data), plotting all values. The mean amplitude and phase of $L_{2}(\mathrm{~T})$ are $\sim 0.007 \mathrm{~K}$ and $\sim 11: 20 \mathrm{am} / \mathrm{pm}$ MLLT, respectively. It is clearly seen that the $L_{2}(T)$ amplitude is smaller than that of $L_{2}\left(T_{a d}\right)$ and that $L_{2}(T)$ precedes $L_{2}\left(T_{a d}\right)$ by $\sim 20$ min. The spread among the stations reflects the geophysical distribution of $L_{2}$ signals (Fig. 2b), as well as observational uncertainty.

The systematic difference between $L_{2}(T)$ and $L_{2}\left(T_{\text {ad }}\right)$ indicates the existence of damping processes exerted on $L_{2}$ near the surface. The least-square estimation of $\beta$ in Eq. (1) from buoy measurements (Methods section) shows that $\beta \sim 6 \times 10^{-5} \exp$ (іт/ $4)$, consisting of not only a real part $\left(\beta_{r}\right)$ but also a significant imaginary part $\left(\beta_{i}\right)$ (Fig. 3b). $\beta_{r}{ }^{-1}$ is $\sim 0.3$ day, which is much shorter than estimates of the purely radiative damping timescale
( $\sim 2$ weeks) and also than the convective damping scale (1-10 days) in the tropical free troposphere. ${ }^{16,17}$

\section{DISCUSSION: NUMERICAL MODEL SIMULATIONS}

Following Sakazaki et al. ${ }^{5}$ we have run a version of a realistic nearglobal climate simulation model with all diurnal variations of solar radiative heating of the troposphere or surface suppressed (the "Remote-F experiment", Methods section). In Remote-F the daily cycle of stratospheric heating excites a solar semidiurnal $\left(S_{2}\right)$ tide which propagates into the troposphere. For the atmosphere just above the tropical ocean surface this produces a situation very analogous to that of the $L_{2}$ tide - a zonal wave 2 westwardtraveling pressure wave with period $12 \mathrm{~h}$ (vs $12.42 \mathrm{~h}$ for $L_{2}$ ) and no local diabatic effects except for those caused by the local longwave radiative damping and sensible heat exchange with the surface (plus any small latent heat release in the air directly above the tropical ocean surface). The same type of experiment was used to investigate the stratospheric role in diurnal cycles in precipitation and in surface pressure solar tides., ${ }^{5,18}$ In this configuration, the model was integrated for 12.5 months $(15 / 11 /$ 1999-30/11/2000) and the results from the final 12 months of data were analyzed. Sakazaki et al. ${ }^{5}$ showed that the overall simulation including seasonal mean tropical rainfall is not strongly affected by the suppression of the tropospheric diurnal solar forcing. To
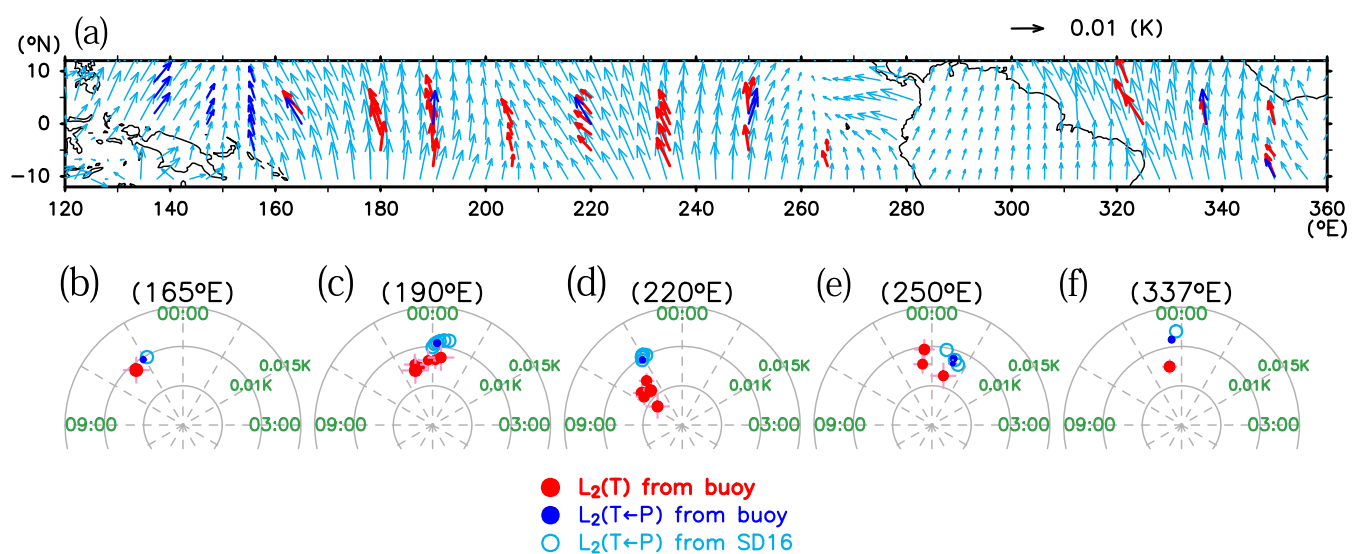

Fig. 2 a Horizontal distribution of harmonic dial vectors over the tropical Pacific and Atlantic ocean for (red) $L_{2}(T)$ from temperature measurements (38 stations), (blue) $L_{2}\left(T_{\mathrm{ad}}\right)$ from pressure measurements (7 stations), and (light-blue) $L_{2}\left(\mathrm{~T}_{\mathrm{ad}}\right)$ from grid dataset by SD16. b-f As (a) but for selected longitudes; only the end points of harmonic dial vectors plotted with the error bars
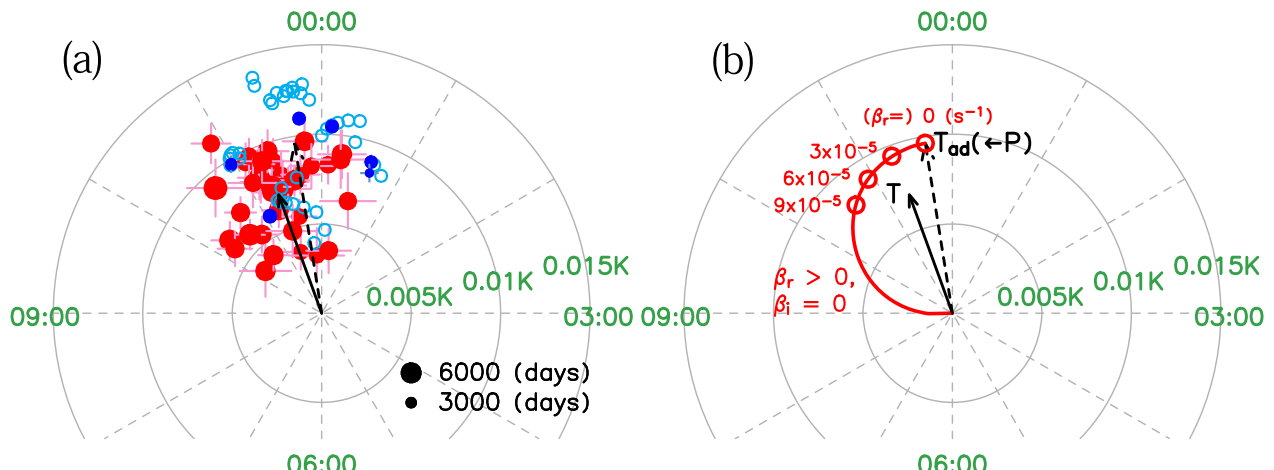

Fig. 3 a Harmonic dial of (red circles) $L_{2}(T)$ and (blue circles) $L_{2}\left(T_{\text {ad }}\right)$ from buoy measurements (38 selected stations for $L_{2}(T) ; 7$ stations for $L_{2}\left(T_{a d}\right)$ ). The results from stations east of $160^{\circ} \mathrm{E}$, where both $L_{2}(T)$ and $L_{2}\left(T_{a d}\right)$ are determined (Fig. 2 ), are shown. The size of each circle denotes the number of days used for the analysis. Horizontal and vertical bars for each datum denote $95 \%$ confidence level with $t$-test (Methods section). Light-blue open circles are from the grid $L_{2}\left(T_{a d}\right)$ data by SD16 for each location of $L_{2}(T)$ measurements. Solid and dashed arrows denote the average harmonic dial vectors for $L_{2}(T)$ from buoys and $L_{2}\left(T_{a d}\right)$ from SD16. $\mathbf{b}$ Two arrows are adopted by those in a. Red curve starting from the averaged $L_{2}\left(T_{a d}\right)$ (dashed black arrow) toward zero indicates the values that $L_{2}(T)$ should take if $\beta$, the coefficient of damping, is allowed to take a real, positive value (red circles show the $L_{2}(T)$ for selected $\beta_{r}$ values) 

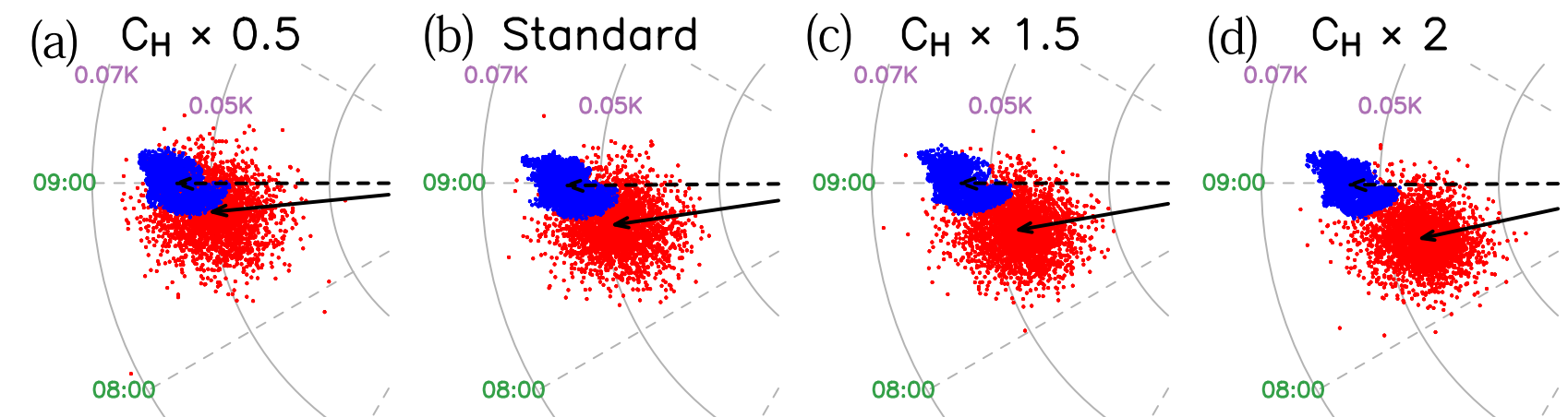

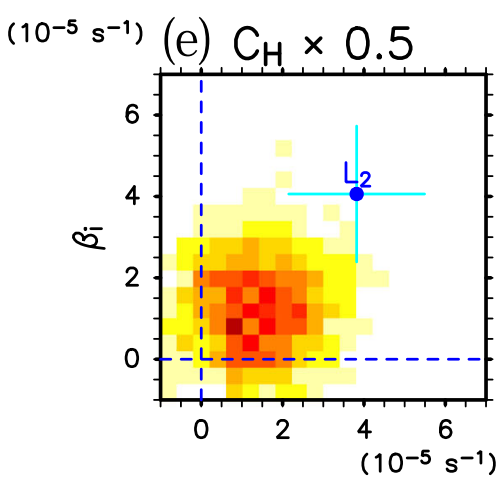

$\beta_{r}$ (f) Standard

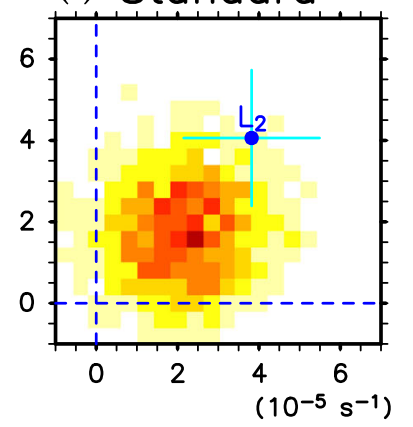

$\beta_{r}$

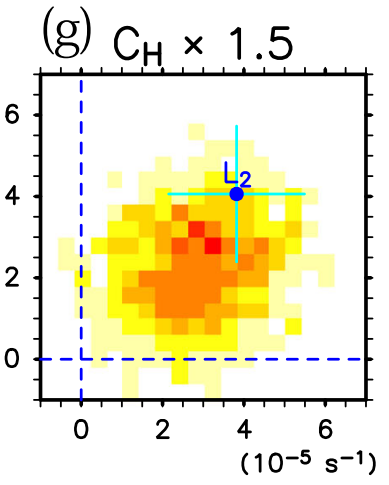

$\beta_{\mathrm{r}}$ (h) $\mathrm{C}_{\mathrm{H}} \times 2$

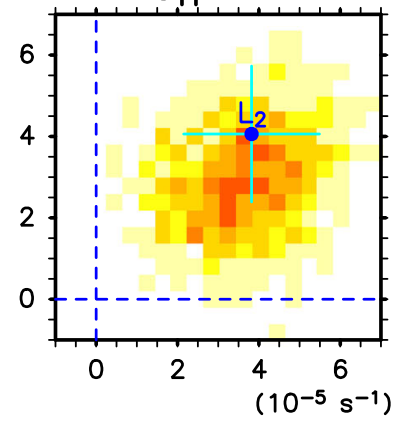

$\beta_{r}$

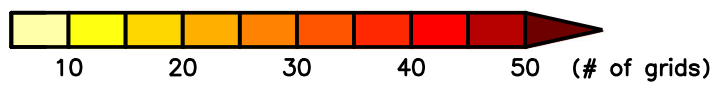

Fig. 4 a-d As is Fig. 3a but for Remote-F model experiments with the $C_{H}$ value relative to the standard values of (a) $50 \%$, (b) $100 \%$, (c) $150 \%$, and (a) $200 \%$. Red and blue dots show the results of $S_{2}(T)$ and $S_{2}\left(T_{a d}\right)$; in the model, $T$ is temperature output at $2 \mathrm{~m}$ and $T_{\text {ad }}$ is calculated by using surface pressure. Only grid points over the tropical Pacific $\left(10^{\circ} \mathrm{S}-10^{\circ} \mathrm{N} ; 160^{\circ}-270^{\circ} \mathrm{E}\right)$ and Atlantic $\left(10^{\circ} \mathrm{S}-10^{\circ} \mathrm{N} ; 330^{\circ}-350^{\circ} \mathrm{E}\right)$ are used for analysis. See Fig. S6 for a different version in which red dots are plotted on top of the blue dots. e-h Frequency distribution of $\beta$ ( $=\beta_{\mathrm{r}}+i \beta_{\mathrm{i}}$ ) from the four model experiments for the tropical Pacific and Atlantic. Blue dots with the error bar shows the estimated $\beta$ from $L_{2}$ observed by buoys

examine the effect of air-sea interaction processes, the Remote-F integration was repeated three more times with the standard surface heat exchange coefficients in the model $\left(C_{H}\right)$ multiplied by factors (i) 0.5 , (ii) 1.5 , and (iii) 2.

Figure $4 a-d$ shows the scatter plots of $S_{2}(T)$ and the $S_{2}\left(T_{a d}\right)$ at the surface for the individual experiments with different $C_{\mathrm{H}}$. Obviously the forcing for the $S_{2}$ tide in the model (stratospheric heating) differs from the gravitational forcing of the $L_{2}$ tide in the real world and so we focus only on the relationship between $S_{2}(T)$ and $S_{2}\left(T_{a d}\right)$. All experiments show that the amplitude of $S_{2}(T)$ is slightly smaller than that of $S_{2}\left(T_{a d}\right)$, while the phase of $S_{2}(T)$ is 10-20 min earlier than $S_{2}\left(T_{a d}\right)$. These characteristics are quite consistent with our buoy observations of $L_{2}$. At the same time, it is obvious that the difference between $S_{2}(T)$ and $S_{2}\left(T_{a d}\right)$ increases, both in amplitude and phase, with increasing $C_{\mathrm{H}}$. This suggests that the thermal interaction between air and sea is largely responsible for the damping process near the surface for a dynamical wave like $L_{2}$ tide.

Figure $4 \mathrm{e}-\mathrm{h}$ shows the histograms of $\beta\left(=\beta_{r}+i \beta_{i}\right)$, over the Pacific and Atlantic oceans, estimated for each experiment. Notably, not only the real part but also the imaginary part has a significant contribution in every experiment. Through all experiments, $\beta$ may be reasonably approximated by, $\beta=B \exp (i \pi / 4)$, where $B$ is the amplitude; but $B$ increases with increasing $C_{H}$, while the phase remains $\sim i \pi / 4$. The phase lag agrees well with our $L_{2}$ buoy measurements, while $B$ best fits in the observed results in case of $C_{H}$ is increased by $50-100 \%$ over the standard value used in this model in earlier climate simulations (including studies with domains extending over tropical oceans ${ }^{19,20}$ ) (Fig. $4 \mathrm{~g}$, h). The sensitivity of $\beta$ to $C_{H}$ found in our model shows that our $L_{2}$ results can be a practical constraint for the parameterization of nearsurface-process in climate models.

Supplementary Information includes a discussion of the heat budget over the $S_{2}$ cycle in our Remote- $F$ model experiments. Note, we can construct heat budgets only at the numerical model levels with the lowest located $\sim 25 \mathrm{~m}$ above the surface (while the $2 \mathrm{~m}$ temperature is computed using similarity theory, Methods section). At altitudes $<500 \mathrm{~m}$, the $S_{2}$ diabatic heating in Remote- $F$ experiment comes largely from parameterized vertical diffusion processes (i.e., the vertical convergence of vertical sensible heat flux $(\tau):-d \tau / d z)$ (Figs. S3 and S4). At the lowest model level $(\sim 25 \mathrm{~m})$ (and presumably also nearer the surface) the phase of $-\mathrm{d} \tau / \mathrm{d} z$ precedes $-T^{\prime}$ by $1-2 \mathrm{~h}\left(\sim \pi / 4\right.$ for $L_{2}$ and $\left.S_{2}\right)$, consistent with the estimated $\beta$. We further find that the phase of $-\mathrm{d} \tau / \mathrm{d} z$ shows an upward progression with altitude, indicating that it takes a finite time for the heat to be transferred upward (Fig. S4). By contrast, $\tau$ itself is found to be in phase with $-T^{\prime}$ (Fig. S2) at the surface $\left(\tau_{s}\right)$, indicating that $\tau_{s}$ varies as a response to local $T^{\prime}$ near the surface. These findings suggest that the damping on dynamical wave near the surface is largely caused by the vertical convergence of upward-propagating sensible heat flux that was injected from the surface due to the air-sea interaction (proportional to $-T^{\prime}$ ). A simple analytical model predicts that the phase lag between the diabatic heating and $-T^{\prime}$ near the surface should be between 0 and $\pi / 2$ (Fig. S5 and Supplementary Information). 
We have observed the $L_{2}$ variation of surface air temperature at multiple locations, allowing us to now clearly determine these key features of $L_{2}$ at low-latitudes: (i) $L_{2}(T)$ is to first order a moonsynchronous signal with $T^{\prime}$ peaking around local lunar noon, (ii) the lunar temperature perturbations are roughly in adiabatic balance with the lunar pressure perturbations, but (iii) there is a clear indication of diabatic damping of the lunar temperature signal. We performed climate model experiments, including a close analogue of the $L_{2}$ tide, by suppressing the daily solar heating cycle in the troposphere; the model results are consistent with our $L_{2}$ observations when reasonable air-sea thermal coupling is included. This experiment is easy to perform and could be the focus for climate model intercomparisons to diagnose air-sea coupling.

\section{METHODS}

Derivation of Equations (1)-(2)

We apply the thermodynamic equation for $L_{2}(\mathrm{~T})$ observed just above $(3 \mathrm{~m})$ the ocean surface. Vertical winds can be ignored, while any effects of mean horizontal advection are also expected to be small as the horizontal phase speed of the tide is much larger than the mean winds near the surface. The equation can be thus written as,

$$
\frac{\partial T \prime}{\partial t}=\frac{R \bar{T}}{C_{p} \bar{p}} \frac{\partial p \prime}{\partial t}+\dot{Q} \rightarrow \frac{\partial T \prime}{\partial t}=\frac{R \bar{T}}{C_{p} \bar{p}} \frac{\partial p \prime}{\partial t}-\beta T \prime,
$$

where $t$ is time; $\dot{Q}$ is $L_{2}$ diabatic heating rate per unit mass $\left(\mathrm{K} \mathrm{s}^{-1}\right) ; T^{\prime}$ and $p^{\prime}$ are $L_{2}(T)$ and $L_{2}(p)$, respectively; $\bar{T}$ and $\bar{p}$ are the mean state temperature and pressure, respectively; $R$ is gas constant; $C_{\mathrm{p}}$ is specific heat of air. $\dot{Q}$ is then represented by an effective Newtonian cooling with the coefficient, $\beta$. When we assume a simple harmonic solution with frequency $\omega$ (i.e., $T^{\prime}=\hat{T} \exp (i \omega t)$ and $\left.p \prime=\hat{p} \exp (i \omega t)\right)$, Equations (1) and (2) are obtained.

\section{Analysis of Moored Buoy data}

We analyze data from moored buoy arrays across the tropical Pacific and Atlantic oceans: the Tropical Atmosphere Ocean/Triangle Trans-Ocean Buoy Network (TAO/TRITON ${ }^{21}$ ) and the Prediction and Research Moored Array in the Atlantic (PIRATA ${ }^{22}$ ), respectively. Since early 1990s, these arrayed buoys have been observing the air temperature and pressure at $3 \mathrm{~m}$ above sea level with a high-temporal resolution $(10 \mathrm{~min}$ to $1 \mathrm{~h}$ for temperature; $1 \mathrm{~h}$ for pressure). The resolution of temperature measurements is $0.01 \mathrm{~K}$ with their accuracy being $0.2 \mathrm{~K}$, while that of pressure measurements is $0.1 \mathrm{hPa}$ with their accuracy being $0.01 \%$. For temperature, we show the $L_{2}$ results obtained with only 10-min data (from 1996 to September 2017) (temperature data from TRITON over the western Pacific (west to $160^{\circ} \mathrm{E}$ ), whose resolution is 1-h, were not used for this study). For pressure, we show the results with hourly data up to September 2017 (there are no 10-min data for pressure). Figure S1 shows the data availability of 10 -min temperature data for each buoy over the entire period up to September 2017. Although there are several data gaps, the measurements have continued over the last two decades.

Data are processed following the so-called Chapman-Miller (C-M) method $^{2,23}$ except that we have employed an extensive quality control in advance to reduce the noise level as described below. First, we pick up days in which more than $60 \%$ are filled with valid data; for temperature (surface pressure) only the stations with the number of days meeting this criteria $>4000(>1500)$ are used for analysis (the criteria for pressure is weaker than that for temperature because the noise level is smaller). For each day (i.e., for 24-h time series), we applied a median-filter three times to eliminate the outliers such that any data outside of 3-sigma level from the median are considered as outliers (the median is calculated within each day with $N-10$ data, with $N$ is the total number of data in the day for every iteration). Finally, the harmonic analysis is performed to extract the $S_{2}$ component. The coefficients for the $S_{2}$ cosine and sine curves are binned for each lunar phase ( $v$ : integer from 0 to 11 , where 0 (6) corresponds to the new/full moon (the half-moon)). Of all binned data for each $v, 50 \%$ around the median in each $v$ are used for further analysis.

The following calculation is based on the C-M method that will be briefly explained here. Let $A_{2}(v)$ and $B_{2}(v)$ be the sum of cosine and sine coefficients, respectively, over binned data for each $v$. The cosine and sine coefficients for lunar semidiurnal signals $\left(I_{a}\right.$ and $\left.I_{b}\right)$ are obtained as,

$I_{a}=\frac{1}{K} \sum_{\nu=0}^{11}\left[A_{2}(\nu) \cos \frac{\nu \pi}{6}+B_{2}(\nu) \sin \frac{\nu \pi}{6}-A_{2}(\nu) \frac{N_{A}}{N}-B_{2}(\nu) \frac{N_{B}}{N}\right]$,

$I_{b}=\frac{1}{K} \sum_{\nu=0}^{11}\left[B_{2}(\nu) \cos \frac{\nu \pi}{6}-A_{2}(\nu) \sin \frac{\nu \pi}{6}-B_{2}(\nu) \frac{N_{A}}{N}+A_{2}(\nu) \frac{N_{B}}{N}\right]$,

where

$N_{A}=\sum_{\nu=0}^{11} N(\nu) \cos \frac{\nu \pi}{6}, \quad N_{B}=\sum_{\nu=0}^{11} N(\nu) \sin \frac{\nu \pi}{6}, \quad N=\sum_{\nu=0}^{11} N(\nu)$,

$K=N\left\{1-\left(\frac{N_{A}}{N}\right)^{2}-\left(\frac{N_{B}}{N}\right)^{2}\right\}$.

Here, the third and fourth terms of Equations (5)-(6) are the correction terms taking into account any non-uniform distribution of days with respect to the lunar phase $(v)$. The amplitude and phase of $L_{2}\left(I_{2}\right.$ and $\lambda_{2}$, respectively, in Eq. (3)) are thus derived as,

$I_{2}=\sqrt{I_{a}^{2}+I_{b}^{2}}, \lambda_{2}=\frac{6}{\pi} \tan ^{-1} I_{b} / I_{a}($ MLLT $)$.

On the other hand, the cosine and sine coefficients of $S_{2}\left(s_{a}\right.$ and $\left.s_{b}\right)$ are obtained by

$s_{a}=\sum_{\nu=0}^{11} \frac{A_{2}(\nu)}{N(\nu)}, s_{b}=\sum_{\nu=0}^{11} \frac{B_{2}(\nu)}{N(\nu)}$

The $S_{2}$ amplitude $\left(s_{2}\right)$ and phase $\left(\varphi_{2}\right)$ are thus

$s_{2}=\sqrt{s_{a}^{2}+s_{b}^{2}}, \phi_{2}=\frac{6}{\pi} \tan ^{-1} s_{b} / s_{a}($ MLST $)$

The associated errors are estimated in the following procedure. We assume that for each day ( $i$-th day), the observed $S_{2}$ component can be actually expressed as

$$
\begin{aligned}
S_{2-\text { obs }}^{i}(\nu)= & s_{2-\text { obs }}^{i} \cos \omega t+s_{2-o b s}^{i} \sin \omega t \\
= & S_{2}+L_{2}(\nu)+\varepsilon_{2}^{i} \\
= & \left(s_{a} \cos \omega t+s_{b} \sin \omega t\right)+\left(I_{a} \cos (\omega t-\nu \pi / 6)\right. \\
& \left.+I_{b} \sin (\omega t-\nu \pi / 6)\right)+\left(\varepsilon_{a}^{i} \cos \omega t+\varepsilon_{b}^{i} \sin \omega t\right)
\end{aligned}
$$

where the first term is the "true" $S_{2}$ independent of lunar phase; the second term is the $L_{2} ;$ the third term is the error. Now that we have obtained $S_{2}$ (Eq. 11) and $L_{2}$ (Eqs. 5-6), $\varepsilon_{a}^{i}$ and $\varepsilon_{b}^{i}$ are calculated for every day; then the errors on the harmonic dial are calculated as

$$
E=\sqrt{\frac{1}{N} \sum_{i}\left(\varepsilon_{a}^{i^{2}}+\varepsilon_{b}^{i^{2}}\right)} / \sqrt{N}
$$

The error bars in Figs. 2 and 3 are defined as the 95\% confidence levels for $E$ with $t$-test (i.e., $\sim 2 E$ ). For $L_{2}(T)$, we show the results at 38 stations with relatively small error bars $(<0.0016 \mathrm{~K}$; this limit is determined by trial-anderror).

\section{Grid $L_{2}$ data from Schindelegger and Dobslaw (2016)}

We use the global grid $L_{2}(p)$ dataset that was developed by Schindelegger and Dobslaw ${ }^{8}$ on the basis of 2315 selected ground-based measurements between 1900 and 2010 from land barometers and moored buoys (including TAO/TRITON and PIRATA used in this paper). It should be noted that they made a correction for the vertical displacement of buoy sensors due to oceanic $L_{2}$ tides. Although such correction terms are nonnegligible, ${ }^{24}$ we use data before the correction; these represent actual $L_{2}(p)$ determination in surface air (data were provided by $M$. Schindelegger, personal communication). For converting the $L_{2}(p)$ to $L_{2}\left(T_{a d}\right)$ for this grid data, mean temperature and surface pressure (coefficients of Eq. 2) are derived from ERA-Interim reanalysis data for the period between 1998 and 2010.

Numerical simulations of $L_{2}$-like variations near the surface We use a comprehensive limited-area atmospheric model developed at the International Pacific Research Center (IPRC) of University of Hawai'i at Manoa, ${ }^{19,20,25}$ which we run in near-global mode. Recently this model was 
used to study solar tides near the surface and their relationship with diurnal cycle in tropical rainfall. ${ }^{5,18}$

We do not directly simulate $L_{2}$ signal (by adding the tidal potential to momentum equations ${ }^{26}$ ), but reproduce $L_{2}{ }^{-}$'like' signals near the surface by running the model with the same configuration of "Remote-forcing (Remote-F) experiment" developed by Sakazaki et al. ${ }^{5}$ That is, the diurnal variation of solar heating in the troposphere and surface is eliminated by replacing the shortwave hearting and the shortwave flux at the surface with the daily-mean values on the same dates in a control run that was performed in advance. In this case, diurnal cycles near the surface are dominated by the $S_{2}$ dynamical tide that is remotely excited in the stratosphere and propagates into the troposphere. Since there is no external, diabatic diurnal forcing near the ground and the frequency of $S_{2}$ is close to that of $L_{2}$, the $S_{2}$ signal near the surface in Remote-F is a close analogue of $L_{2}$.

The model is run in near-global zonal strip mode with SSTs and lateral boundary conditions at $75^{\circ} \mathrm{S}$ and $75^{\circ} \mathrm{N}$ specified from observational reanalyses. The integration is from $11 / 15 / 1999$ to $11 / 30 / 2000$; the 1-year data from $12 / 1 / 1999$ to $11 / 30 / 2000$ are used for the actual analysis. In order to examine the effect of heat exchange between air and surface on the $L_{2}(T)-L_{2}\left(T_{a d}\right)$ relationship, the Remote-F experiment was repeated with surface heat exchange coefficient $\left(C_{H}\right)$ changed by: (1) $50 \%$ decrease, (2) $50 \%$ increase, and (3) $100 \%$ increase.

Temperature at $2 \mathrm{~m}$ in altitude $\left(\mathrm{T}_{2 \mathrm{~m}}\right)$ in the model is calculated based on the similarity theory of the surface layer. Diabatic heating due to the vertical mixing processes near the surface are calculated using the Mellor-Yamada-Nakanishi-Niino scheme. ${ }^{27}$

\section{Estimation of damping coefficient}

By using the relationship between $L_{2}(T)$ and $L_{2}\left(T_{\text {ad }}\right)$ for 38 buoy stations $\left(L_{2}(T)\right.$ is from direct measurements while $L_{2}\left(T_{a d}\right)$ is from SD16 data), the Newtonian cooling coefficient has been estimated. From Eq. (1), $\beta$ is determined $(\bar{\beta})$ with the least-squares-method so that the following quantity, $L$, takes the minimum.

$L=\sum_{n}\left|(i \omega+\bar{\beta}) \hat{T}^{n}-i \omega \hat{T}_{\text {ad }}^{n}\right|^{2}$,

where $\omega$ is the wave-frequency $(=2 \pi / 12.42 \mathrm{~h}), \hat{T}^{n}$ and $\hat{T}_{\text {ad }}^{n}$ are the complex amplitudes of $L_{2}(T)$ and $L_{2}\left(T_{a d}\right)$ at $n$-th station (e.g., $L_{2}(T)=\hat{T}^{n} \exp (i \omega t)$ ). The uncertainty of the estimated $\beta$ is defined as

$E=\sqrt{\frac{1}{N_{S}} \sum_{n}\left|\beta^{n}-\bar{\beta}\right|^{2}} / \sqrt{N_{S}}$,

where $N_{s}$ is the number of stations (38) and $\beta^{n}$ is determined for each station as,

$\beta^{n}=i \omega\left(\frac{\hat{T}_{\mathrm{ad}}^{n}}{\hat{T}^{n}}-1\right)$.

The $95 \%$ confidence level (with $t$-test) is defined as $2 \mathrm{E}$ ( $t$-value for the degree of freedom of 38 is 2).

\section{Data availability}

Buoy data can be obtained through the web site of the Pacific Marine Environmental Laboratory: https://www.pmel.noaa.gov/tao/drupal/disdel/. Model results will be publically available at the Asia-Pacific Data-Research Center (APDRC) at IPRC (http://apdrc.soest.hawaii.edu/).

\section{ACKNOWLEDGEMENTS}

We thank Dr. Chunxi Zhang and Dr. Yuqing Wang for the use of their model and for their practical assistance, and Dr. Michael Schindelegger for providing the original $L_{2}$ grid dataset. We also thank Dr. Henryk Dobslaw and one anonymous reviewer for their instructive comments for improving the manuscript. T.S. was supported by the Japan Society for Promotion of Science. Figures 1-4, S1-4 and S6 were drawn with the GFD-DENNOU Library. The IPRC is partly supported by the Japan Agency for Marine-Earth Science and Technology (JAMSTEC).

\section{AUTHOR CONTRIBUTIONS}

T.S. and K.H. designed the analysis and numerical experiments. T.S. performed the data analysis and the numerical experiments. K.H. and T.S. wrote the paper.

\section{ADDITIONAL INFORMATION}

Supplementary information accompanies the paper on the npj Climate and Atmospheric Science website (https://doi.org/10.1038/s41612-018-0033-9).

Competing interests: The authors declare no competing interests.

Publisher's note Springer Nature remains neutral with regard to jurisdictional claims in published maps and institutional affiliations.

\section{REFERENCES}

1. Haurwitz, B. \& Chapman, S. Lunar air tide. Nature 213, 9-13 (1967).

2. Chapman, S. \& Lindzen R. S. Atmospheric Tides, (ed Reidel, D.) 200 p, (1979).

3. Chapman, S. Notes on the lunar geomagnetic tide: I-Its mathematical and graphical representations, and their significance. Terr. Magn. Atmos. Electr. 47, 279-294 (1942).

4. Kohyama, T. \& Wallace, J. M. (2016), Rainfall variations induced by the lunar gravitational atmospheric tide and their implications for the relationship between tropical rainfall and humidity. Geophys. Res. Lett. 43, 918-923 (2016).

5. Sakazaki, T., Hamilton, K., Zhang, C. \& Wang, Y. Is there a stratospheric pacemaker controlling the daily cycle of tropical rainfall? Geophys. Res. Lett. 44, 1998-2006 (2017).

6. Sabine, E. On the lunar atmospheric tide at St. Helena. Philos. Trans. R. Soc. Lond. 137, 45-50 (1847)

7. Haurwitz, B. \& Cowley, D. The lunar barometric tide, its global distribution and annual variation (1969). Pure Appl. Geophys. 77, 122-150 (1969).

8. Schindelegger, M. \& Dobslaw, H. A global ground truth view of the lunar air pressure tide $\mathrm{L}_{2}$., J. Geophys. Res. Atmos. 121, 95-110 (2016).

9. Geller, M. An investigation of the lunar semidiurnal tide in the atmosphere. J. Atmos. Sci. 27, 202-218 (1970).

10. Vial, F. \& Forbes, J. M. Monthly simulations of the lunar semi-diurnal tide. J. Atmos. Terr. Phys. 56, 1591-1607 (1994).

11. Chapman, S. The lunar diurnal variation of atmospheric temperature at Batavia, 1866-1928. Proc. R. Soc. A137, 1-24 (1932).

12. Chapman, S. On the theory of the lunar tidal variation of atmospheric temperature. Mem. R. Meteorol. Soc. 4, 35-40 (1932).

13. Fels, S. B. A parameterization of scale-dependent radiative damping rates in the middle atmosphere. J. Atmos. Sci. 39, 1141-1152 (1982).

14. McLandress, C. The seasonal variation of the propagating diurnal tide in the mesosphere and lower thermosphere. Part I: the role of gravity waves and planetary waves. J. Atmos. Sci. 59, 893-906 (2002).

15. Lewis, J. M., Koracin, D. \& Redmond, K. T. Sea fog research in the United Kingdom and United States. Bull. Am. Meteor. Soc. 85, 395-408 (2004).

16. Wu, Z., Battisti, D. S. \& Sarachik, E. S. Rayleigh friction, Newtonian cooling, and the linear response to steady tropical heating. J. Atmos. Sci. 57, 1937-1957 (2000).

17. Romps, D. M. Rayleigh damping in the free troposphere. J. Atmos. Sci. 71, 553-565 (2014).

18. Sakazaki, T. \& Hamilton, K. Physical processes controlling the tide in the tropical lower atmosphere investigated using a comprehensive numerical model. J. Atmos. Sci. 74, 2467-2487 (2017).

19. Wang, Y., Sen, O. L. \& Wang, B. A highly resolved regional climate model (IPRCRegCM) and its simulation of the1998 severe precipitation event over China. Part I: model description and verification of simulation. J. Clim. 16, 1721-1738 (2003). 1721:AHRRCM.2.0.CO;2.

20. Stowasser, M., Wang, Y. \& Hamilton, K. Tropical cyclone changes in the western north Pacific in a global warming scenario. J. Clim. 20, 2378-2396 (2006).

21. McPhaden, M. J. et al. The tropical ocean global atmosphere observing system: a decade of progress. J. Geophys. Res. 103, 14169-14240 (1998).

22. Bourles, B. et al. The PIRATA program: history, accomplishments and future directions. Bull. Am. Met. Soc. 89, 1111-1125 (2008).

23. Malin, S. R. C. \& Chapman, S. The determination of lunar daily geophysical variations by the Chapman-Miller Method. Geophys. J. R. Astr. Soc. 19, 15-35 (1970).

24. Hollingsworth, A. The effect of ocean and Earth tides on the semi-diurnal lunar air tide. J. Atmos. Sci. 28, 1021-1044 (1971).

25. Wang, Y., Zhou, L. \& Hamilton, K. Effect of convective entrainment/detrainment on the simulation of the tropical precipitation diurnal cycle. Mon. Wea. Rev. 135, 567-585 (2007)

26. Pedatella, N. M., Liu, H.L. \& Richmond, A. D. Atmospheric semidiurnal lunar tide climatology simulated by the Whole Atmosphere Community Climate Model. J. Geophys. Res. 117, A06327 (2012).

27. Nakanishi, M. \& Niino, H. Development of and improved turbulence closure model for the atmospheric boundary layer. J. Meteorol. Soc. Jpn. 87, 895-912 (2009). 
Open Access This article is licensed under a Creative Commons Attribution 4.0 International License, which permits use, sharing, adaptation, distribution and reproduction in any medium or format, as long as you give appropriate credit to the original author(s) and the source, provide a link to the Creative Commons license, and indicate if changes were made. The images or other third party material in this article are included in the article's Creative Commons license, unless indicated otherwise in a credit line to the material. If material is not included in the article's Creative Commons license and your intended use is not permitted by statutory regulation or exceeds the permitted use, you will need to obtain permission directly from the copyright holder. To view a copy of this license, visit http://creativecommons. org/licenses/by/4.0/.

(c) The Author(s) 2018 